\title{
Perfil intelectual del padre Ania (1671-1733): censuras, libros y lecturas
}

Padre Ania's intellectual profile (1671-1733): aprobaciones, books and readings

Guillermo Fernández Ortiz

Universidad de Oviedo

CES.XVIII, núm. 26 (2016), págs. 299-330

Este trabajo ha sido desarrollado en el marco de una investigación financiada por el programa «Severo Ochoa» de la FiçT de la Consejería de Cultura y Educación del Principado de Asturias (España). 


\section{RESUMEN}

En el primer tercio del siglo XVIII fray Joaquín de Ania (1671-1733) fue uno de los personajes más destacados de la Congregación cisterciense de Castilla. Conocida su trayectoria política, el objetivo de las presentes líneas es diseccionar su perfil intelectual. Para ello analizamos su obra escrita - cuatro censuras y un memorial- y ofrecemos algunos apuntamientos sobre sus libros personales y sus lecturas. Veremos cómo, frente a la opinión extendida, entre los cistercienses castellanos hubo gente de elevado nivel cultural.

Palabras clave

Fray Joaquín de Ania, Cistercienses, Censura positiva, Paratextos, Historia de la Cultura Escrita.

\section{Abstract}

In the first third of the 18th century, Joaquín de Ania (1671-1733) was one of the most distinguished figures from the Cistercian Congregation of Castile. Known his political path, the objective of the present lines is to know his intellectual profile. We analyze his written works — four «aprobaciones» and a brief_ — and we offer some notes on his personal library. We will see like, opposite to the widespread opinion, among the Castilian Cistercians there were people of high cultural standard.

KEY WORDS

Joaquín de Ania, Cistercians, ‘Aprobación’, Paratexts, History of Written Culture.

Recibido: 22 de febrero de 2016. Aceptado: 29 de junio de 2016. 
El objetivo de la presente investigación es delinear el perfil intelectual de fray Joaquín de Ania (1671-1733) quien, en el primer tercio del siglo XVIII, se constituyó como uno de los personajes más carismáticos de la Congregación cisterciense de Castilla. Para ello, en primer lugar, nos servimos de los textos (literarios) que él mismo escribió, valorando, previamente, la naturaleza y el carácter de la fuente. En segunda instancia, para colmar las expectativas, hemos logrado recabar diversas noticias sobre su librería personal, al entender esta como «retrato de las inquitudes intelectuales» de su propietario ${ }^{1}$.

\section{Trazos biográficos y cursus honorum ${ }^{2}$}

Procedente de una familia de la pequeña hidalguía regional asturiana, en 1691, Ania profesa en el monasterio leonés de Nuestra Señora de Sandoval cuando apenas cuenta con veinte años de edad. Aún desconocemos dónde inicia estudios, pero, acreditada la etapa formativa por la universidad de Ávila, convalida los grados obtenidos en el instituto abulense en el centro universitario de Alcalá de Henares. Se doctora en Sagrada Teología, desempeña labores docentes en el colegio de San Bernardo de Alcalá y hacia 1713 se halla residiendo en la Corte al estimarle el capítulo general de la Observancia cisterciense castellana como sujeto adecuado para opositar a cátedras en la academia complutense $e^{3}$. De ello tenemos el testimonio del propio Ania hacia 1716. También por esos años

1 Así lo expone, entre otros muchos, Agustín Hevia Ballina, «La biblioteca clásica del padre Feijoo», en II Simposio sobre el padre Feijoo y su siglo, volumen I, Oviedo, Ayuntamiento de Oviedo, 1981, pág. 375.

2 María Damián Yáñez NeIrA, «Ania (Joachim)», en Émile Brouette, Anselme Dimier et Eugène Manning (dirs.), Dictionnaire des auteurs cisterciens, Rochefort, 1975, pág. 47. Un estudio más amplio de su trayectoria vital, sobre documentación de archivo, puede verse en Guillermo FernándEz OrTIZ, «Fray Joaquín de Ania. Un antiguo abad del Colegio de Nuestra Señora de Belmonte (Asturias) en la aprobación al tomo III del Teatro crítico universal», en Inmaculada Urzainqui y Rodrigo Olay Valdés (eds.), Con la razón y la experiencia. Feijoo 250 años después, Oviedo, Instituto Feijoo de Estudios del Siglo XVIII / Ayuntamiento de Oviedo / Trea / Universidad de Oviedo, (en prensa). Salvo excepción indicada, las noticias sobre su vida están tomadas de este texto, donde han sido ampliamente documentadas.

3 El capítulo general de los bernardos castellanos pudo, en efecto, considerarle como un buen candidato para opositar a las cátedras de Alcalá y seguramente por ello él mismo haga ostentación; ahora bien, hasta el momento no he podido documentar tal oposición entre los fondos de la Universidad de Alcalá. 
empieza a tomar partido en las disputas internas que sacuden a la Congregación cisterciense de Castilla ${ }^{4}$.

Desde entonces, los puestos de responsabilidad se suceden. En 1717 es elegido para ocupar la silla abacial en Belmonte, un pequeño cenobio emplazado en el corazón de Asturias, último en unirse a los bernardos castellanos, y que desde mediados del siglo XVII funciona como colegio de Filosofía. En 1721 el capítulo general le estima como el hombre idóneo para guiar, en el trienio 1721-1724, los designios de la Observancia castellana. Esta se hallaba, desde tiempo atrás, inmersa en una profunda crisis interna ${ }^{5}$, aún mal conocida en todas sus manifestaciones, pero en la que en los años de su mandato no se aprecian las disensiones de las décadas inmediatas, tanto de la antecedente como de la posterior ${ }^{6}$.

En esos años cruza correspondencia con el poder real y reenvía sus órdenes y disposiciones a los monasterios que integran la Congregación cisterciense de Castilla, rasgo explícito del eminente carácter centralizado y jerárquico que tiene la Observancia ${ }^{7}$, pero también de las atribuciones de la Corona en materia religiosa.

Tras ocupar el cargo más prestigioso entre los cistercienses castellanos, en 1724, es elegido para ostentar la silla abacial del monasterio urbano que la Observancia tenía en la Villa y Corte: el de Santa Ana o San Bernardo de Madrid. Al frente de esta casa se mantendrá hasta 1727, si bien seguirá siendo su residencia en el trienio siguiente, hasta 1730. Desde entonces y hasta su muerte, acaecida en 1733, seguirá participando en los asuntos de los bernardos.

4 E. Martín, Los Bernardos españoles (Historia de la Congregación de Castilla de la Orden del Císter), Palencia, gráficas Aguado, 1953, págs 75 y ss.

5 José Miguel López García, La transición del Feudalismo al Capitalismo en un señorío monástico castellano. El abadengo de la Santa Espina (1147-1835), Valladolid, Junta de Castilla y León, 1990, págs. 125-131 y 395-399. Guillermo FERnÁNDEZ ORTIZ, «La crisis de los bernardos castellanos según un impreso de la biblioteca universitaria de Zaragoza. Estudio y edición», Cuadernos de Estudios Borjanos, LIx (2016), págs. 137-146.

6 Aunque presiones desde fuera no faltaron. A cargo de un franciscano corrió la Demostracion de hecho por el Patronato Real en los Monasterios de Campos, y Galicia de la Congregación de Monte-Sion de Toledo, del Orden de Cistèr, ò de nuestro Padre San Bernardo. Contra el Memorial presentado en Roma à la Santidad de Clemente XI de feliz memoria, intitulado: palabras, ò Restricto de los Annales del orden de Cistercienses, sobre la fundacion de los Monasterios de Campos, y Galicia, sacado de los Annales en los lugares infracitados. En la que se manifiesta la nulidad del fundamento capital de la distribución, que se asignò en un Breve espedido en tres de Octubre del año de 1710, elaborado en 1722, en el cual se sostiene, monasterio a monasterio, cómo las casas cistercienses referidas pertenecían al Patronato Real; expone sus conclusiones del folio 50 en adelante. Citamos por el ejemplar que se conserva en la BNE.

7 Sobre esta cuestión: Guillermo Fernández OrTiz, «Cartas de relación, correspondencia epistolar y prácticas archivísticas en el monasterio cisterciense de Nuestra Señora de Belmonte (Asturias) durante la Edad Moderna», en Sociedad y Escritura: el clero (en prensa). 
No fueron, no obstante, estos los únicos cargos que desempeñó. Fue también elegido definidor general dos veces, la última en el capítulo reunido en $\mathrm{Pa}$ lazuelos en mayo de $1727^{8}$. En esta ocasión lo fue junto a Francisco de Quirós, hijo del monasterio de Valdediós. En ese año fue elegido también como primer escrutador 9 . Designado nuevamente como tal en el siguiente capítulo general —el de 1730—, será en esta ocasión el encargado de hacer pública la elección del nuevo General Reformador ${ }^{10}$.

Además de esta trayectoria política, el padre Ania, durante sus residencias madrileñas, actuó como censor y aprobante. No conocemos los informes manuscritos, pero, de este desempeño, sí nos constan las cuatro piezas paratextuales, compuestas entre 1716 y 1729, en las que cumplió la misión censora que se le había encomendado y que se publicaron entre los preliminares de las obras a las que concedió la aprobación.

Sabemos que su labor como escritor no se ciñó únicamente a estas breves piezas, pero, por el momento, no tenemos mayor noticia de la obra Emblemas o máximas morales, autógrafa de Ania, que ya a finales del siglo XVIII se daba por perdida $^{11}$.

Para aproximarnos a su perfil intelectual hemos logrado recabar también unas breves notas sobre su biblioteca personal, la cual, según era preceptivo entre los bernardos, pasó, tras su muerte, a su monasterio de profesión, saliendo algunas obras luego en almoneda. Finalmente, hemos podido manejar un polémico impreso, escrito hacia 1714-1715 para condenar el contenido de un memorial que el procurador de la Observancia de los bernardos castellanos en Madrid había elevado al rey sin autorización del capítulo general ${ }^{12}$. Uno de los responsables de su elaboración fue el propio Ania.

8 Como tal suscribe en mayo de ese año. AHN. Sección Clero Regular y Secular. Cistercienses. Palazuelos. Libro 16521. Libro de Actas de los Capítulos Generales de la Congregación, fol.745r.

9 AHN. Sección Clero Regular y Secular. Cistercienses. Palazuelos (Valladolid). Libro 16521. Libro de Actas de los Capítulos Generales de la Congregación, fols. 749v., 750v. y 759v.

10 AHN. Sección Clero Regular y Secular. Cistercienses. Palazuelos (Valladolid). Libro 16521. Libro de Actas de los Capítulos Generales de la Congregación, fols. 762v.-763v. También lo será en 1733 contra su voluntad (AHN. Sección Clero Regular y Secular. Cistercienses. Palazuelos (Valladolid). Libro 16521. Libro de Actas de los Capítulos Generales de la Congregación, fol. 774v.).

11 Roberto MuñIz, Biblioteca cisterciense española, Burgos, don Joseph Navas, 1793, pág. 28.

12 Biblioteca Universitaria de Zaragoza.- G-72-424(5), fols. 487r.-492r. [Memorial de Ania y San Martín, fols. 1r.-6r.]. Ha sido editado en Guillermo Fernández OrTiz, «La crisis de los bernardos castellanos», págs. 146-153. 
Del padre Ania conocemos cuatro censuras o aprobaciones ${ }^{13}$. La primera la redacta hacia 1716, coincidiendo con el último año de su primera residencia conocida en Madrid. Firma entonces, en el monasterio de Santa Ana, la censura a la Disciplina religiosa de fray Juan de San Ángel ${ }^{14}$. El resto, las compone durante su última estancia madrileña, una vez deja de desempeñar el cargo abacial en el cenobio que los bernardos tenían en la Corte ${ }^{15}$. Con fecha de 6 de julio de 1727 firma la aprobación al Defensorio sobre la religiosidad de los caballeros militares del conde de Aguilar ${ }^{16}$. En ese mismo año le es remitido el tomo tercero del Teatro crítico universal del padre Feijoo, aunque el visto bueno definitivo no lo da hasta comienzos de $1728^{17}$. Y, finalmente, en octubre de ese mismo año compone la censura encomendada al Ferreras convencido con crítico desengaño del padre Berganza ${ }^{18}$. Son estas censuras o aprobaciones las que nos han de permitir trazar su perfil literario y una vía de aproximación fundamental al intelectual.

Algunos de estos paratextos han sido localizados gracias a las noticias suministradas por F. Aguilar Piñal, en su bibliografía de autores españoles del

13 A lo largo de las presentes páginas, para agilizar su lectura, emplearemos ambos términos como sinónimos. Previamente establecemos los matices y las implicaciones específicas de ambos conceptos. De un modo similar proceden José Simón Díaz, El libro español antiguo. Análisis de su estructura, Kassel, editions Reichenberger, 1983, pág. 100; Antonio SÁnchez JiménEZ, «La musa casera: poesía de circunstancias y estética bajobarroca en el Ramillete poético de las discretas flores (1706) de José Tafalla Negrete», Cuadernos de Estudios del Siglo XVIII, 25 (2015), pág. 230, donde utiliza ambos conceptos como sinónimos. También emplea indistintamente los términos aprobar y censurar Ignacio García Agullar, Poesía y edición en el Siglo de Oro, Madrid, Calambur, 2009, págs. 90 o 100. Incluso Víctor Pampliega, que trabaja sobre los informes de censura que se custodian en el AHN, se manifiesta de este modo. Víctor Pamplega Pedreira, Las redes de la censura: el Consejo de Castilla y la censura libraría en el siglo XVIII, Tesis Doctoral, Madrid, Universidad Complutense de Madrid, 2013, págs. 280 y 341.

14 Juan de SAn ÁngEL, Disciplina religiosa en consideraciones espirituales y reflexiones morales de las obligaciones de los religiosos. Exposición literal, mística, moral y Histórica de la Regla del Preexcelso Padre San Alberto, Patriarca de Jerusalén, Legado a Latere del Oriente, como se professa en todo el Orden de la Madre de Dios del Carmen, Madrid, Viuda de Matheo Blanco, 1717.

15 Sobre la enorme dedicación que suponía emplearse en la censura de textos se ha manifestado Víctor Pampliega Pedreira, Las redes de la censura en el siglo XVIII, págs. 331 y 333.

16 Íñigo De la Cruz Manrique de Lara, Defensorio de la religiosidad de los cavalleros militares, comprobado con authoridades de los mismos authores que contra ellos se citan de que son simpliciter, y verdaderamente religiosos, por ley, por razón y por authoridad, y de que como tales deben gozar de todos los privilegios de religiosos, Madrid, Bernardo Peralta, 1731.

17 Benito Jerónimo FejJoo, Theatro crítico universal, tomo III, Madrid, Francisco del Hierro, 1729.

18 Francisco de Berganza, Ferreras convencido, con crítico desengaño en el tribunal de los doctos con los chronicones corregidos que escribieron el rey don Alonso III, dicho el Magno, Sampiro, obispo de Astorga, Pelagio, obispo de Oviedo, Isidro, obispo pacense, el anónymo Iriense, Madrid, Francisco del Hierro, 1729. 
siglo XVIII ${ }^{19}$. Por su parte, fray Roberto Muñiz daba cuenta de un «Dictamen sobre el Defensorio» que hemos podido identificar también como pieza paratextual ${ }^{20}$. Mientras, Fermín Canella, entre los méritos que recogía del padre Ania, incluía la aprobación al tomo segundo del Teatro de Feijoo ${ }^{21}$. No tengo noticia de que se conserven en el Archivo Histórico Nacional otras censuras debidas a su pluma, censuras en las que podía haber ofrecido un dictamen negativo $^{22}$. Tampoco en las licencias de impresión al Ferreras de Berganza ${ }^{23}$ $o$ en el privilegio al Teatro de Feijoo ${ }^{24}$ hay referencia alguna a su aprobación. Parece evidente que los dictámenes emitidos por los censores que actuaron a petición de la vicaría eclesiástica madrileña hubieron de tomar una vía administrativa paralela ${ }^{25}$, ajena en todo caso al procedimiento que se abría en el consejo de Castilla con la súplica del autor o del impresor ${ }^{26}$. Es decir, su desempeño permanecía desconocido y anónimo para el Consejo, pues a este únicamente llegaba el juicio y dictamen del vicario eclesiástico de Madrid. Desconozco si entre los expedientes que se conservan en el Archivo Diocesano

19 Francisco Agullar Piñal, Bibliografía de autores españoles del siglo XVIII. Tomo IV. G-K, Madrid, CSIC, 1986, pág. 752; y del mismo Bibliografía de autores españoles del siglo XVIII. Tomo II. C-CH, Madrid, CSIC, 1983, págs. 704-705.

20 Roberto MuÑz, Biblioteca cisterciense, pág. 28.

21 Biblioteca de Asturias «Ramón Pérez de Ayala». Fondo Canella, manuscritos: Panteón: Voz: «Ania, Joaquín de», folios 1v.-2r.

22 Describe los caracteres de la documentación Vanesa Benito Ortego, «El consejo de Castilla y el control de las impresiones en el siglo XVIII. La documentación del Archivo Histórico Nacional», Cuadernos de Historia Moderna, 36 (2011), págs. 179-193, especialmente págs. 185-188. Por otra parte, Ania no figura en la lista de censores del siglo XVIII que ofrece Víctor Pampliega quién trabajó abundantemente con las censuras manuscritas que se conservan en el Ahn. Víctor Pampliega Pedreira, Las redes de la censura en el siglo XVIII, págs. 488-516. El motivo es, sin duda, que Ania actuó como censor, como veremos, a instancias del vicario eclesiástico de Madrid y no directamente a petición del consejo de Castilla.

23 La vía administrativa es la del expediente. En el mismo papel de la súplica se van anotando los diferentes pasos del procedimiento hasta la concesión de la licencia o del privilegio. AHN Consejos. Legajo 50627. Expediente 65. «Remítese a la censura del lizenciado don Lucas Ortiz, relator del Real Consejo de Castilla». No hay noticia de la censura que el vicario encarga a Ania.

24 Ni rastro de la censura de Ania. Sin embargo, sí se incluyen los términos esenciales del parecer de don Pedro de la Torre. AHN. Consejos. Legajo. 50627. Expediente 112. «Remítese a la zensura del doctor don Pedro Gómez de la Torre, penitenciario de la Santa Yglesia de Obiedo y colegial de San Bartolomé». Más adelante se recoge el dictamen «M. P. S. Señor. De orden de V. A., e visto el terçer tomo que quiere imprimir el suplicante y no ay en él cosa en que se ofenda a las regalías de V. M. Salvo meliori. Oviedo y enero, $1^{\circ}$ de 1729. Don Pedro de la Torre (R)».

25 En todo caso la vía es nuevamente la habitual, la del expediente.

26 A finales de siglo, únicamente llegaba al Consejo el certificado de la autoridad intermedia (el vicario eclesiástico de Madrid). Fernando Durán LóPEZ, «Regalías, traducciones y devociones indiscretas: una cala en la censura religiosa de libros a fines del XVIII», en Fernando Durán López (coord.), Instituciones censoras: nuevos acercamientos a la censura de libros en la España de la Ilustración, Madrid, CSIC, 2016, pág. 69. Con anterioridad, Lucienne Domergue, La censure des libres en Espagne à la fin de l'Ancien Régime, Madrid, Casa Velázquez, pág. 93. 
de Madrid hay otras censuras del padre Ania. De las ya referidas, he manejado exclusivamente las aprobaciones impresas.

\section{La aprobación. De informe administrativo a ejercicio literario}

Pese a los rasgos rutinarios, los topoi habituales y la retórica abultada que se aprecian en esta clase de piezas paratextuales y pese a que durante mucho tiempo a censuras y aprobaciones, así como a casi cualquier otro tipo de paratexto, se les confirió escaso o nulo valor literario ${ }^{27}$, en fechas recientes el estado de opinión ha cambiado y se han comenzado a valorar positivamente las posibilidades que ofrece su estudio ${ }^{28}$, tanto desde el punto de vista literario como del de la historia de las ideas ${ }^{29}$. De hecho, una de las mayores especialistas en la materia, Anne Cayuela, ha llegado a hablar de las aprobaciones como género literario ${ }^{30}$, y no es la única ${ }^{31}$. Alain Bègue la ha seguido en sus planteamientos ${ }^{32}$ y Michel Moner ha llamado la atención sobre el interés que tendría abarcar la totalidad paratextual de un autor ${ }^{33}$, sin desestimar la relación entre texto y paratexto, senda (o, quizás mejor dicho, sendas) en la(s) que ya se han adentrado, y con éxito, José Simón, Pedro Álvarez de Miranda o la propia Anne Cayuela ${ }^{34}$, entre otros. Por su parte,

27 Michel Moner, «Introducción. El paratexto: ¿para qué?», en María Soledad Arredondo, Pierre Civil y Michel Moner (eds.), Paratextos en la literatura española (siglos XV-XVIII), Madrid, Casa de Velázquez, 2009, pág. XI.

28 Expone el alcance de estas investigaciones en el marco de los estudios sobre la Historia de la Cultura Escrita Antonio Castillo Gómez, «¿Qué escritura para qué historia?», en Antonio Castillo Gómez (ed.), Cultura del escrito en el Mundo Occidental. Del Renacimiento a la Contemporaneidad, Madrid, Casa de Velázquez, 2015, pág. 8.

29 José Simón Díaz, El libro español antiguo, págs. 110-111. Las posibilidades que ofrecen pueden verse en el estudio de Elena Cano TurRión, «Retóricas Paratextuales académicas entre dos siglos. El entorno zaragozano», Cuadernos de Estudios del siglo XVIII, 25 (2015), págs. 63-66.

30 Anne Cayuela, Le paratexte au siècle d'Or, Ginebra, Droz, 1996.

31 Fermín de los Reyes Gómez, El libro en España y América. Legislación y censura (Siglos XV-XVIII), I, Madrid, Arco/Libros, 2000, pág. 358.

32 Alain BÈGue, «De leyes y poetas. La poesía de entre siglos a la luz de las aprobaciones (siglos XVIIXVIII)», en María Soledad Arredondo, Pierre Civil y Michel Moner (eds.), Paratextos en la literatura española. Siglos XV-XVIII, Madrid, Casa Velazquez, 2009, pág. 92.

33 Michel Moner, «El paratexto: ¿para qué?», pág. XII. Sobre este aspecto se ha pronunciado también José Simón Díaz, El libro español antiguo, pág. 111.

34 José Simón Díaz, El libro español antiguo, págs. 99-113. Pedro Álvarez de Miranda, «Los paratextos de las obras de Feijoo», en Inmaculada Urzainqui y Rodrigo Olay Valdés (eds.), Con la razón y la experiencia. Feijoo 250 años después, Oviedo, Instituto Feijoo de Estudios del Siglo XVIII / Ayuntamiento de Oviedo / Trea / Universidad de Oviedo, (en prensa). Anne Cayuela, «Mira de Amescua, censor y panegirista de Bernardo de Balbuena», en Agustín de la Granja y Juan Antonio Martínez Berbel (eds.), Mira de Amescua en Candelero. Actas del Congreso Internacional sobre Mira de Amescua y el Teatro Español del Siglo XVII (Granada, 27-30 octubre 1994) I, Granada, Universidad de Granada, 1996, págs. 187-199, en particular págs. 187-188. 
Inmaculada Urzainqui, en el exhaustivo estudio introductorio al tomo II de la edición completa de las obras del padre Feijoo, utiliza ampliamente este tipo de piezas paratextuales para conocer la difusión de la obra del padre maestro, su perfil literario, o la imagen de su persona compuesta por alguno de sus allegados ${ }^{35}$. Tampoco es la única que ha transitado el camino ${ }^{36}$ y el propio Pedro Álvarez de Miranda ha demostrado su utilidad para el estudio del léxico de la Ilustración temprana, especificamente la relación entre ideas y palabras ${ }^{37}$.

Al margen de lo expuesto, no menos sugestivo sería afrontar el estudio de estas piezas paratextuales desde el concepto de «género editorial», acuñado por Infantes ${ }^{38}$, en la medida en que las propias aprobaciones deben su carácter literario a los rasgos que configuran un panorama editorial en el que la materialidad libraria está condicionada — entre otros muchos factores, por supuesto- por un cuadro jurídico-legislativo determinado. En esencia, bien puede afirmarse que las aprobaciones toman ese carácter (literario) en la medida en que el propio sistema editorial está diseñado para que, en efecto, sean impresas. En caso contrario, en el supuesto de haber permanecido manuscritos y ocultos, los dictámenes apenas habrían sobrepasado su carácter de informes administrativos, no teniendo esta dimensión literaria. De hecho, una vez que se prohibe su impresión, el ejercicio literario desaparece y el texto queda reducido a la consignación del trámite administrativo, más extenso, eso sí, en el caso de una resolución negativa ${ }^{39}$.

En un principio, si nos atenemos a su naturaleza jurídica, esto es, a su fundamentación legal y razón de ser, la aprobación no dejaba de ser una censura

35 Inmaculada UrzainQui, «Estudio introductorio», en Benito Jerónimo Feijoo, Obras completas, tomo II. Cartas eruditas y curiosas, I. Edición crítica de Inmaculada Urzainqui y Eduardo San José Vázquez, Oviedo, Instituto Feijoo de Estudios del Siglo XVIII, 2014, págs. 23, 26, 27, 53, 64, 87, 105 y 108.

36 Véanse, por ejemplo, las notas biográficas que ofrece Isaac Vázquez en su artículo sobre Soto y Marne, y que proceden, en su mayoría, de aprobaciones y de otras piezas paratextuales. Isaac VÁZQuEz JANEIRO, «Fray Francisco Soto y Marne. Impugnador de Feijóo», Boletín Auriense, 4 (1974), págs. 167-198. Los ejemplos que se podrían aducir son numerosos.

37 Pedro Álvarez de Miranda, Palabras e ideas. El léxico de la Ilustración Temprana en España (16801760), Madrid, Anejos del Boletín de la Real Academia Española, 1992.

38 Víctor Infantes De Miguel, «La tipología de las formas editoriales», en Nieves Baranda, Víctor Infantes de Miguel, François López y Jean-François Botrel (dirs.), Historia de la edición y de la lectura en España (1472-1914), Madrid, Fundación Germán Sánchez Ruipérez, 2003, pág. 43. Víctor Infantes de Miguel, «Los géneros editoriales: entre el texto y el libro», en Manuel Peña Díaz, Pedro Ruiz Pérez y Julián Solana Pujalte (coords.), La Cultura del libro en la Edad Moderna. Andalucía y América, Córdoba, Universidad de Córdoba, 2001, pág. 38, donde expone «cerca del $80 \%$ de los textos poéticos de nuestra literatura de cordel no se hubieran escrito (literariamente) si no se iban a editar». Solo hace falta sustituir el sujeto por el de «la mayoría de las censuras positivas».

39 Señala esa reducción Víctor Pampliega Pedreira, Las redes de la censura en el siglo XVIII, págs. 50, $314,328-329,332$ y 441. 
favorable, un trámite administrativo que se constituía como la emisión de un juicio positivo a la obra que se evaluaba, necesario para que fuera impresa, al ser elemento constitutivo de la censura previa ${ }^{40}$, distinta de la censura inquisitorial, formada a posteriori $^{41}$, y siempre bajo el control de la monarquía, y, en el caso de un religioso, también bajo la supervisión de sus superiores. Por supuesto, el juicio podía ser también desfavorable, en cuyo caso la obra no llegaba a las prensas y el dictamen del censor permanecía oculto ${ }^{42}$.

En el primer tercio del siglo XVIII, el panorama no distaba en lo esencial de la realidad documentada en los siglos anteriores ${ }^{43}$. Así, como expone Domergue,

[...] un autor del estado religioso [...] necesitaba, para dar a la imprenta cualquier libro suyo, nada menos que tres censuras: la primera era la del prelado de su orden [...]; las otras dos [...] se desempeñaban por encargo del Consejo de Castilla: una era confiada por este al vicario eclesiástico de Madrid [...], mientras la otra se confiaba por mandato directo del Consejo, a algun censor particular o cuerpo literario ${ }^{44}$.

A juicio de la investigación, la carta de naturaleza de censuras y aprobaciones hubo de encontrar asiento defintivo en la Pragmática de Felipe II de $1558^{45}$, si bien, sabemos que ya con anterioridad se imprimían y que desde Trento se

40 La censura previa ha sido estudiada por Esteban Conde Naranjo, El Argos de la Monarquía. La policía del libro en la España ilustrada (1750-1834), Madrid, Centro de Estudios Políticos y Constitucionales, 2006. Más reciente, Víctor Pampliega Pedreira, Las redes de la censura en el siglo XVIII. Este último no propone una definición de la voz aprobación. Para nuestros intereses una definición operativa puede ser la que ofrece el Diccionario de Autoridades, en su tomo primero, de 1726: «calificación y abono que se hace de alguna persona o cosa, dándola por buena, digna de estimación y de ley» Diccionario de la lengua castellana en que se explica el verdadero sentido de las voces, su naturaleza y calidad..., I, Madrid, Francisco del Hierro, 1726, pág. 358. En la definición de aprobar se especifica: «Calificar, y dar por buena y de ley una cosa, como un libro, una obra». Así se explica también el carácter «extrajudicial» de algunas aprobaciones impresas.

41 Marcelin Defourneaux, Inquisición y censura de libros en la España del siglo XVIII, Madrid, Taurus, 1973, págs. 26 y 52. También: Antonio Mestre SAnchis y Pablo Pérez García, «La cultura en el siglo XVIII español», La Cultura española en la Edad Moderna, Madrid, ediciones Istmo, 2004, págs. 391-392. En idénticos términos se expresa Ceferino CARo LóPEz, «Los libros que nunca fueron. El control del Consejo de Castilla sobre la imprenta en el siglo XVIII», Hispania, LXII/1, 213 (2003), pág. 165.

42 Víctor Pampliega Pedreira, Las redes de la censura en el siglo XVIII, pág. 441.

43 Esteban Conde Naranjo, El Argos de la Monarquía, pág. 20. Sobre la continuidad de la práctica y la vigencia de la legislación anterior al cambio dinástico en Castilla se manifiesta François LoPEz, «La legislación, control y fomento», en Nieves Baranda, Víctor Infantes de Miguel, François López y Jean-François Botrel (dirs.), Historia de la edición y de la lectura en España (1472-1914), Madrid, Fundación Germán Sánchez Ruipérez, 2003, págs. 275 y ss.

44 Lucienne Domergue, «La censura en los albores de las luces: el caso del padre Feijoo y sus "aprobantes"», en VV. AA., Estudios dieciochistas. En homenaje al profesor José Miguel Caso González. Oviedo, Instituto Feijoo de Estudios del siglo XVIII, 1995, pág. 228.

45 Esteban Conde Naranjo, El Argos de la Monarquía, págs. 19-20 (nota 23). 
contemplaba su llegada a la estampa ${ }^{46}$. En todo caso, desde 1558, para que un libro llegase a las prensas era precisa la licencia real, previa actuación del Consejo de Castilla ${ }^{47}$. En el primer tercio del siglo XVIII, la legislación de los Austrias al respecto, en la corona de Castilla, seguía plenamente vigente.

Estas aprobaciones y censuras, concebidas como un trámite administrativo, adquirían carácter literario y, junto con el resto de testimonios del arduo procedimiento administrativo de control (licencia de impresión, privilegio, fe de erratas y tasa) salían impresas delante del texto, constituyéndose en una suerte de preliminares legales, testigos públicos de la censura a priori ${ }^{48}$.

Sin embargo, también el autor podía designar aprobantes y censores para su propia obra ${ }^{49}$.

Según hemos referido repetidas veces, el padre Ania actúa como tal, al menos, entre 1716 y $1729^{50}$. En tres ocasiones lo hace por mandato del vicario eclesiástico en la villa de Madrid y su partido ${ }^{51}$ y, en una, según parece, a peti-

46 Fermín de los Reyes Gómez, El libro en España y América. También José Simón Díaz, El libro español antiguo, págs. 5-16.

47 «Otrosí defendemos y mandamos que ningún libro ni obra de qualquier facultad que sea en latín ni en romance ni otra lengua se pueda imprimir ni imprima en estos Reynos sin que primero el tal libro o obra sean presentados en nuestro Consejo y sean vistos y examinados por la persona o personas a quien los del nuestro Consejo lo cometieren y hecho esto se le dé licencia firmada de nuestro nombre y señalada de los del nuestro Consejo [...] y que en principio de cada libro que así se imprimiere se ponga la licencia y tasa y privilegio si le hubiere». Novísima Recopilación. Título XVI. Ley III. Pragmática de Felipe II de 7 de septiembre de 1558. En lo que atañe a las aprobaciones, la legislación sería completada con el auto del Consejo de 3 de julio de 1626. Novísima Recopilación. Título XVI. Ley VIII, donde se recoge que «no se impriman libros de qualquier calidad compuestos o traducidos por religiosos o regulares si no fuere trayendo aprobación de sus superiores y de el Ordinario donde residieren».

48 Anne Cayuela, Le paratexte au siècle d'Or, pág. 16.

49 Antonio Mestre SAnchis, «Reflexiones sobre el marco político y cultural de la obra del padre Feijoo», Apología y crítica de España en el siglo XVIII, Madrid, Marcial Pons, 2003, pág. 180. La práctica estaba vigente en el siglo XVIII: Ceferino CARo LóPEz, «El control del Consejo de Castilla sobre la imprenta en el siglo XVIII», pág. 169. Podían tratarse de «censuras extrajudiciales» o de piezas de recomendación: Esteban CoNDE Naranjo, El Argos de la Monarquía, págs. 115 y 147. También Víctor Pampliega Pedreira, Las redes de la censura en el siglo XVIII, págs. 321-322.

50 Hubo individuos que desempeñaron en no pocas ocasiones las funciones de censor civil y eclesiástico, Anne Cayuela, «Mira de Amescua, censor», pág. 187. También José Simón Díaz, El libro español antiguo, págs. 26 y 107-108.

51 Para la obra del carmelita fray Ángel de San Juan el texto que redacta Ania le es encomendado por «orden del Licenciado Don Nicolás de la Paz Hermosino, teniente-vicario de la Villa de Madrid y su Partido». Lo mismo ocurre con las aprobaciones al tomo III del Teatro crítico universal de Feijoo y al Ferreras convencido de Berganza. Respectivamente: «de orden del señor doctor don Francisco Lozano, canónigo de la Santa Iglesia Magistral de Alcalá de Henares, Inquisidor Ordinario y vicario de la villa de Madrid y su Partido» y «de orden y comisión de el señor doctor don Christoval Damasio, canónigo del Sacromonte, extramuros de la ciudad de Granada, inquisidor ordinario, y vicario de esta villa de Madrid y su partido». Es un aspecto en el que incide ligeramente Víctor Pampliega Pedreira, Las redes de la censura en el siglo XVIII, págs. 167-168 y 311-312. 
ción del propio autor ${ }^{52}$. Así, fray Joaquín, como era por otra parte preceptivo y por ello lugar común, dado que, como censor, lo que se esperaba de él era que diese, o no, el visto bueno a la obra, concluye sus informes con cláusulas del siguiente tenor que, por otra parte, responden a modelos habituales: «Tan lexos como esto vivo de percibir en esta Obra suya cosa, ni aún leve, contra nuestra Sagrada Fe y buenas costumbres» o «assí lo siento como también en que no contiene este libro cláusula que haga dissonancia a los dogmas de nuestra Santa Fe y buenas costumbres: Salvo meliori». Significativo resulta, por tanto, que omita en todas ellas la referencia a «las regalías de su Magestad», pasaje que completa la fórmula más convencional ${ }^{53}$. Por supuesto, no es el único que se manifiesta así ${ }^{54}$, aún cuando otros censores que emiten su dictamen por orden del vicario de Madrid se sirven de la expresión en todo su desarrollo ${ }^{55}$. No obstante, sí parece claro que es una decisión personal del propio Ania optar por expresarse de ese modo, aunque no sea, ni mucho menos un proceder extraño.

En su ejercicio de censura a priori, el aprobante podía, antes de emitir un dictamen positivo, imponer la supresión de ciertos pasajes, párrafos o palabras $^{56}$, cuando no impedir la publicación de un libro. No faltan casos conocidos

52 El Defensorio sobre la religiosidad del conde de Aguilar va precedido por más de 150 censuras, pareceres, dictámenes y aprobaciones, la inmensa mayoría a petición del propio autor. Así, el que fuera catedrático de prima de la Universidad de Salamanca, fray Juan de Aliaga, escribe «Haviéndose dignado el Excelentíssimo señor frey don Ýñigo de la Cruz Manrique de Lara [...] de remitirme un libro, obra de su Excelencia [...] para que diesse mi parecer sobre su contenido». Fray Melchor de Morales, antiguo abad del cenobio que los benedictinos tenían en Corias (Asturias), por su parte, escribe: «haviendo merecido al Excelentíssimo Señor Conde de Aguilar, mi Señor, el favor singular de mandarme decir mi sentir sobre la eruditíssima obra que ha compuesto en defensa de la Religiosidad». Sobre las «garantías» derivadas de la acumulación de aprobaciones se ha expresado Fermín de Los Reyes Gómez, El libro en España y América, I, pág. 357. Ofrece otro ejemplo Ignacio García Aguilar, Poesía y edición, pág. 103.

53 Víctor Pampliega Pedreira, Las redes de la censura en el siglo XVIII, págs. 82-83, 99 y 357-359.

54 Un laico, el doctor José Suñol, médico de cámara de Felipe V, escribía «no solo no tiene cosa digna de reparo contra nuestra Santa Fe Cathólica y buenas costumbres» Francisco SuÁrez DE Ribera, Medicina ilustrada, chýmica observada, Madrid, Francisco del Hierro, [1725?]. Censura de José Suñol [sin foliar].

55 El licenciado José Suárez y Yabar concluye la aprobación que le encomienda el vicario madrileño a la obra de Joseph Pradillo Cirugía triunfante demonstrativa, Madrid, Francisco del Hierro, 1728, del siguiente modo: «no hai [...] cosa que pueda ofender respecto de nuestra Santa Fe, costumbres ni regalías de su Magestad». De todos modos, como expone Fernando Durán, a fines del siglo XVIII la referencia a las regalías no era habitual en los juicios de los censores designados por el vicario eclesiástico de Madrid. Fernando Durán LóPEZ, «Regalías, traducciones y devociones», pág. 81.

56 Así se ha expuesto para la vecina Francia. Robert Netz ha sintetizado el status social de los censores regios en el país galo, su escasa remuneración, su nivel cultural, la falta de sistematización en la tarea y la actuación censora sobre la obra; en Robert NETZ, Histoire de la censure dans l'édition, París, Puf, 1997. págs. 49-50. Para España, Víctor PAmPliega Pedreira, Las redes de la censura en el siglo XVIII, págs. 79, 319, 327,340 y 396 , donde señala la concesión de licencia de impresión a condición de que el autor cumpliera con las modificaciones indicadas por el censor. Con anterioridad fue anotado por Lucienne Domergue, La censure des libres en Espagne, págs. 74 y 78. 
desde el siglo $\mathrm{XVI}^{57}$. Así, aunque Ania concluye la aprobación al volumen III del Teatro crítico universal del padre Feijoo del siguiente modo: «con que no conteniendo, como no contiene, esta obra cosa opuesta a las verdades de Nuestra Sagrada Católica Religión ni a la pureza de las buenas costumbres, sería compasión privar al público de erudición tan amena y dilatada. Así lo siento, salvo meliori etc», sabemos que tardó varios meses en dar su visto bueno. De hecho, no lo hizo hasta que fueron suprimidos o eliminados ciertos pasajes ${ }^{58}$.

Ahora bien, en los años finales del siglo XVII y primeros del XVIII lo que en inicio había sido un requisito legal se convierte en una oportunidad para expresar, en términos laudatorios, los méritos del texto y las dotes del autor ${ }^{59}$. $\mathrm{Y}$, además, supone un vehículo idóneo para exponer programas, ideas ${ }^{60} \mathrm{y}$, en fin, aparecer ofreciendo al público un desempeño literario de marcado carácter erudito. Es decir, previo al dictamen que se le ordenaba formar, el aprobante realizaba un ejercicio literario, frecuentemente a modo de panegírico del autor y de la obra que le tocaba juzgar. En este, desarrollaba su genio creador, al tiempo que podía mostrar ante los demás su capacidad de erudición ${ }^{61}$. Pero no solo esto sino que además estos textos le permitían aparecer en el panorama público — puede decirse político— manifestando su adhesión a un grupo, a un bando cortesano o, simplemente, mostrando su preferencia por las propuestas defendidas por determinado sector intelectual. Y fue este desplazamiento de la razón de ser original de las aprobaciones lo que motivó la crítica a tal pro-

57 Anne Cayuela, Le paratexte au siècle d'Or, pág. 21. Fermín de los Reyes Gómez, El libro en España y América, I, págs. 262-263 y 356. José Simón Díaz, El libro español antiguo, pág. 105. También se refiere al particular, Beatriz RodríguEz RodríguEz, Del original de imprenta al libro impreso antiguo, Madrid, Ollero y Ramos, 2014, pág. 60.

58 Maximino Arias, «Catorce cartas de Feijoo al padre Sarmiento», Boletín del Centro de Estudios del siglo XVIII, 4-5 (1977), pág. 21. Le escribía Feijoo a Sarmiento: «En este correo rezibo carta de el illustríssimo en que me dice no se qué de embrollos de el padre Ania sobre aprobación i alboroto de los capuchinos sobre la espeçie que toco de el padre Carabantes, añadiendo que supone Vuestra Merced me avrá escrito una i otra espeçie; y como no he tenido otra que esta, confusa i vaga, que me da su illustríssima, lo que discurro es que los capuchinos, sabidores de lo que escribo de su missionero Carabantes, hizieron con Ania que negasse o suspendiesse la aprobaçión». En principio, la elección de censor era secreta, no siendo comunicada a quien solicitaba la licencia para imprimir una obra. Sabemos, no obstante, que, en la práctica, los autores sabían quiénes censuraban sus textos con relativa asiduidad. También el censor podía ponerse en contacto con el autor para indicarle modificaciones Víctor Pampliega Pedreira, Las redes de la censura en el siglo XVIII, págs. 126 у 336.

59 José Simón Díaz, El libro español antiguo, pág. 108. Alain Bègue, «La poesía a la luz de las aprobaciones (siglos XVII-XVIII)», págs. 93-95. También Víctor PAmpliega Pedreira, Las redes de la censura en el siglo XVIII, pág. 127.

60 Pedro Álvarez de Miranda, «Los paratextos de las obras de Feijoo».

61 Idéntica apreciación hace Víctor Pampliega Pedreira, Las redes de la censura en el siglo XVIII, págs. 368 y 408. 
ceder de Interián de Ayala ${ }^{62}$, al que Otero Pedrayo llama «censor de todos los censores» ${ }^{63}$, siguiendo el calificativo de los compañeros de claustro de Feijoo. Para los monjes de San Vicente de Oviedo el paratexto estaba más que justificado: «calificamos por censura lo que parece panegýrico del autor, porque elogiar los censores a los escritores cuyos libros aprueban es práctica común fundada en la recta razón» ${ }^{64}$.

Pese a ello, no se descuida en ningún caso la disposición del texto. Todas las aprobaciones suyas que conocemos siguen la estructura habitual de este tipo de piezas según las ha caracterizado Simón Díaz ${ }^{65}$. Sin embargo, el desplazamiento de que hablamos es tan palpable, que cuando Ania escribe su dictamen al Defensorio sobre la religiosidad de los militares del conde de Aguilar —recordemos, a petición del propio autor-, el editor, a buen seguro, abrevia precisamente la cláusula en la que certifica que la obra no contiene nada contra la fe y las buenas costumbres: «Y assí lo sentimos etcétera».

Por lo tanto, en primer lugar Ania da cuenta de quién le ordena componer la aprobación y, en última instancia, certifica que la obra no contiene nada en contra de la religión y de las buenas costumbres. Finaliza todas las piezas paratextuales con la data tópica, la cronológica y su suscripción. En otro lugar ya hemos expuesto como toda su actividad como censor la desempeñó mientras residió en la Corte, en el monasterio de Santa Ana o San Bernardo de Madrid ${ }^{66}$.

\section{Contenido de las aprobaciones: tópicos y metáforas}

Ahora bien, entre ambas cláusulas — las de apertura y cierre que acabamos de referir-, Ania realiza su ejercicio literario. En él no faltan tópicos que se repiten de unas aprobaciones a otras. Entre ellos quizás destaque el recurso me-

62 Benito Jerónimo Fejoo y Montenegro, Theatro crítico universal, II, Madrid, Francisco del Hierro, 1728. Censura del Reverendísimo padre maestro fray Juan Interián de Ayala.

63 Ramón Otero Pedrayo, El padre Feijóo. Su vida, doctrina e influencias, Orense, Instituto de Estudios Orensanos Padre Feijóo, 1972, pág. 155.

64 Benito Jerónimo Feijoo y Montenegro, Theatro crítico universal, III, Madrid, Francisco del Hierro, 1729. Aprobación de los Reverendísimos Padres Maestros, Regente y Lectores de Theología, del Colegio de San Vicente de la ciudad de Oviedo.

65 José Simón Díaz, El libro español antiguo, 1983, págs. 99 y ss. También Ignacio GarCía Aguilar, Poesía y edición, pág. 97.

66 «Con dificultad se podrá encontrar en el siglo XVIII un escritor de importancia que, por uno u otro motivo, no haya tenido que pisar la Villa y Corte, bien como residente, bien como "pretendiente" o simple viajero» Francisco Aguilar PIÑal, Introducción al siglo XVIII, Madrid, Júcar, 1991, pág. 25. Hay edición corregida y aumentada, Francisco Aguilar Piñal, La España del absolutismo ilustrado, Madrid, Espasa-Calpe, 2005, pág. 52. 
tafórico a la palabra luz, de uso frecuente en la literatura del período. En ocasiones la emplea como sinónimo de capacidad intelectual («luzes de su talento»), caso que Álvarez de Miranda documenta también en Martí, Feijoo, Isla... ${ }^{67}$, mientras que en otras aparece vinculado a sus antónimos tinieblas, oscuridad, sombras («dissipa con luz activa las nubes»). Estas últimas — las sombrasaparecen asociadas al paso del tiempo, que todo lo oculta, o, junto a ello, a la falta de instrucción («exponiendo a la luz pública los diplomas pontificios que por seguridad o por incuria estuvieron ocultos por muchos siglos»). Por lo tanto, no es extraño que también emplee la voz luz vinculada a la transmisión de conocimientos y saberes por medio del estudio y del escrito, dando lustre o esplendor a los mismos («bañar de luzes sus escritos»). En este mismo sentido documentamos el verbo ilustrar que emplea, tal como figura en una de las acepciones del Diccionario de Autoridades: aclarar mediante explicaciones y comentarios («el indecible modo con que ilustra su assumpto»).

Ania se sirve también de otras metáforas como la del navío que con buen rumbo se dirige a su destino y que también documentamos en otros autores ${ }^{68}$, o ya de ciertos tópicos no menos habituales en censuras y aprobaciones como la cantidad de veces que se ha leído la obra que juzga («Con indecible fortuna, gusto y atención havemos leído repetidas vezes el libro intitulado Defensa de la religiosidad» $)^{69}$, que esta «merece más gracias que censura» ${ }^{70}$, o que no se excederá en alabanzas al autor porque sería ofender su modestia ${ }^{71}$.

67 Pedro Álvarez de Miranda, El léxico de la Ilustración Temprana en España, págs. 176-178.

68 Lo emplea Feijoo en el Teatro. El pasaje lo recoge Giovanni STIFFoni, «Intelectuales, sociedad y Estado», en José María Jover Zamora (dir.), Historia de España Menéndez Pidal Tomo XxIx La época de los primeros Borbones (volumen II). La Cultura española entre el Barroco y la Ilustración (1680-1759), Madrid, Espasa-Calpe, 1985, pág. 77.

69 En la aprobación de Agustín de Loaysa a Francisco Lozano Román, Descripción Histórica, Chronológica y Genealógica... de Génova, Madrid, Diego Martín Abad, 1729, podemos leer: «después de aver leído todo el libro bolví a leer muchas partes de él». Mientras, en la censura de fray Joseph Suárez y Yabar a la obra de Joseph Pradillo, Cirugía triunfante demonstrativa, Madrid, Francisco del Hierro, 1728, este escribe: «Leí esta cirugía triunfante por obediencia una vez, por gusto muchas».

70 Pedro Álvarez de Miranda recoge el siguiente fragmento de 1724: «No solo se le deve la licencia que pide [...] sino también muchas gracias porque prosigue en ilustrar» (Pedro Álvarez DE Miranda, El léxico de la Ilustración Temprana en España, pág. 190). Ofrece otras expresiones similares, tomadas de los expedientes de censura conservados manuscritos en el Archivo Diocesano de Madrid, Fernando Durán LópEz, «Regalías, traducciones y devociones», pág. 84.

${ }^{71}$ En la aprobación a la obra del conde de Aguilar puede leerse: «porque estos elogios aunque verdaderos son desiguales a la altura del mérito del author, que sabe merecerlos y no oírlos, passo a decir mi dictamen de la obra». Por su parte, Tomás Navarro en la aprobación a la Oración de Mayans en alabanza de Saavedra Fajardo escribe: «Ni me llevará el afecto de patricio y amigo ni ofenderé la modestia del autor con estudiosas alabanzas» (recogido en Pedro Álvarez de Miranda, El léxico de la Ilustración Temprana en España, pág. 253). 
Pese al menguado número de aprobaciones de que disponemos ${ }^{72}$, estos últimos pasajes sirven para ilustrar cómo, en su desempeño literario, Ania dirige su atención en una doble dirección: el autor y su obra, analizando de esta contenido y estilo, sin desaprovechar la ocasión para expresar su opinión sobre algún aspecto concreto de la misma. De todos modos, esta forma de proceder no fue exclusiva del asturiano, sino que tal manera de articular la materia tratada en el paratexto era similar de unos aprobantes a otros. En otra de las aprobaciones al Defensorio sobre la religiosidad, el padre maestro Agustín de Castejón ${ }^{73}$ escri- $^{-}$ bía: «partiré mi censura en tres términos, que serán: sugeto, assumpto y el modo con que está escrito».

En primer lugar Ania dedica siempre unas elogiosas palabras a los autores y ello incluye los cuerpos a que cada uno de ellos pertenecía. En el caso de los religiosos no falta la referencia a la orden en que profesan ${ }^{74}$, mientras que, en la aprobación a la obra de don Íñigo de la Cruz, junto a la mención de rigor al hábito que luce («el amor debido al Sagrado Instituto que professa en la Ýnclita Religión de Calatrava»), el elogio afecta también al linaje, dado que la grandeza, el mérito y en definitiva la condición humana eran, en el Antiguo Régimen, hereditarias ${ }^{75}$. El pasaje no puede ser más expresivo:

Y, si alguna vez pudo tener lugar aquella sentencia de que basta registrar el nombre de los authores para dar segura aprobación a sus escritos (Si auctor non

72 Estamos muy lejos de la cifra de censuras y aprobaciones debidas a otras manos. Víctor PAMPLIEGA PedReIRA, Las redes de la censura en el siglo XVIII, págs. 242-245, 269, 275 y 283-284. Es de sobra conocido el caso de Lope de Vega. Florentino Zamora Lucas, Lope de Vega, censor de libros. Colección de aprobaciones, censuras, elogios y prólogos del Fénix que se hallan en los preliminares de algunos libros de su tiempo, Larache, Artes Gráficas Boscá, 1941.

73 Sabemos de este Agustín de Castejón participando activamente en la contienda contra Feijoo. Inmaculada UrZainQui, «Estudio introductorio», pág. 30.

74 A propósito de la obra de Berganza escribe «para calificación de esta obra bastaba haverse formado en aquellos claustros [de la Congregación de San Benito], que son la más sabia y rígida Escuela de virtud y erudición, en donde aún el ocio es estudio, el silencio habla y las paredes enseñan, no dexando jamás de ser discípulos como mýsticas piedras que con recíproca colisión se pulen y anivelan para formar el templo de la sabiduría». Parte de pasaje recuerda al capítulo 48 de la regla de San Benito donde se expone: «La ociosidad es enemiga del alma; por eso han de ocuparse los hermanos a unas horas en el trabajo manual y en otras en la lectura divina». Cito por La Regla de San Benito (introducción y comentario de García M. Colombás), Madrid, Biblioteca de Autores Cristianos, 1979, pág. 147.

75 Por ejemplo, en la censura del padre José Tirado, compuesta por orden del vicario en la Villa de Madrid, Francisco Lozano Román, a la Descripción Histórica, Chronológica y Genealógica [...] de Génova [...] de Juan Félix Francisco Rivarola Pineda (Madrid, Diego Martín Abad, 1729), mayorazgo de Rivarola, no falta la referencia de rigor al linaje, cuyo mérito está al nivel del asumpto tratado en la obra. 
displicet opus probemus), ninguna ocasión más oportuna que esta, en que el author, por la elevación de su excelsa prosapia, talentos y aplicación, puede bañar de luzes sus escritos y coronarlos al mismo tiempo de tantos laureles inseparables de su grandeza heredada y adquirida ${ }^{76}$.

Todos ellos eran personajes bien conocidos y reconocidos en su tiempo, hecho ya suficiente para la aprobación de sus obras, tópico no menos habitual. En todo caso, los religiosos habían hecho carrera en sus respectivas órdenes (Feijoo y Berganza en la orden benedictina - Congregación de Valladolid — y fray Juan de San Ángel en la del Carmelo), mientras que el conde de Aguilar la había hecho en el ejército. Además, en el campo de las letras ninguno de ellos era un neófito, pues todos habían hecho llegar a la estampa alguna obra digna de mérito.

Fray Juan de San Ángel fue un hombre de prestigio en su tiempo y, al margen de sus quehaceres religiosos como predicador general, llegó a ser cronista provincial de Castilla. Había llevado ya a las prensas otro texto que había gozado de opinión favorable en su día: las Tres vidas del Hombre ${ }^{77}$. Ania no puede sino reconocerle como «maravilloso Artífice», «maestro verdaderamente grande», para, a continuación, aducir el valor de sus libros ya publicados. En la aprobación al tomo tercero del Teatro crítico universal recuerda «los dos tomos antecedentes [...] que salieron a luz, con admiración y aplauso universal de los sabios [...], claro testimonio de la indecible copia de erudición del autor», mientras que en la censura que forma para el Ferreras convencido del padre Berganza no puede omitir referirse a aquellas «obras que el autor dio al público con aprobación universal, especialmente aquellos dos celebrados tomos de Antigüedades de España» ${ }^{78}$.

El conde de Aguilar, por su parte, ya había hecho púbicos otros textos ${ }^{79}$, pero Ania prefiere destacar junto a su desempeño como escritor su calidad de soldado, pues al servicio de Felipe V había combatido en Milán:

[...] escritor de tan alto grito que hace enmudecer la antigua y reñida disputa entre armas y letras, colocándolas en igual sublime grado en el trono de su

$76 \quad$ El subrayado, salvo por cuestiones orto tipográficas, es nuestro.

77 Juan de SAN Ángel, Libro de las tres vidas de el hombre, corporal, racional y espritual. Su autor el iluminado y extático varón el venerable padre fray Miguel de la Fuente... segunda impresión. Corregida y añadida con el índice de las cosas más notables y un dibuxo de la vida del venerable padre, Madrid, Imprenta Real, 1710.

78 No era este un tópico extraño. Así, en 1724, fray Francisco Uvalia, en la aprobación que compone por orden del vicario en la villa de Madrid, Cristobal Damasio, a la Medicina ilustrada o chýmica observada o teatros... de Francisco SuÁrez de Ribera (Madrid, Francisco del Hierro, s. a.) se expresa en términos similares: «los libros de este grande autor, todos son aventajados».

79 Íñigo de la Cruz Manrique de Lara, Theses mathemáticas, Cádiz, Colegio de la Compañía de Jesús, 1688. 
ánimo augusto o haciendo que se equivoquen con transformación nunca oída pues supo convertir la espada en pluma quando con caracteres de sangre enemiga escrivió en el papel de las campañas el derecho incontrastable de nuestro monarca Philipo ${ }^{80}$.

Esta apreciación de Ania que pudiera parecer extraña, está, sin lugar a dudas, directamente relacionada con dos cuestiones: de un lado, un tópico habitual que se registra en la literatura desde el Quinientos —el tópico de las armas y las letras $^{81}$ — , y, de otro, un lamento generalizado tanto entre historiógrafos como entre religiosos a lo largo de los siglos XVI-XVII-y Ania, como habremos de ver no era un profano en ninguna de estas materias—: el hecho de que en la Edad Media, durante toda la Reconquista, los españoles estuvieron muy preocupados en las armas, pero apenas fomentaron el cultivo de las letras ${ }^{82}$. Conjugar ambas suponía por tanto una virtud nada desdeñable.

Antes de entrar a valorar el contenido de las obras que juzga, Ania dedica unas líneas, aunque no siempre, para tratar del estilo con que se manifiestan los autores. Del de San Ángel escribe «es natural sin desasseo, hermoso sin artificio y claro sin molesta difussión. Es digno del autor y de la materia, [...], sin aquel mundano peregrino adorno que ultraja más que hermosea pluma y doctrina de tanta elevación». En términos similares expone el de Íñigo de la Cruz: «El estilo, magestuoso y claro, añade nuevo peso a las razones que propone. Es correspondiente a obra tan grande y es digno del Héroe que escribe [...], conforme a la gravedad de los argumentos y elegante sin artificio». Por lo tanto, está claro que en el discurso, Ania admira la claridad, la concisión, la naturalidad, la ausencia de $\operatorname{artificios}^{83}$, ser conforme a la entidad de los asuntos tratados y finalmente hacer prevalecer en él la razón.

80 Íñigo de la Cruz ManriQue de Lara, Defensorio de la religiosidad de los cavalleros militares. Censura del padre Ania.

81 Se refiere a la cuestión Miguel BatLlori, Humanismo y Renacimiento. Estudios hispano-europeos, Barcelona, Ariel, 1987, págs. 30-31; también Jorge GARCía LóPEz, «El estilo de una corte: apuntes sobre Virgilio Malvezzi y el laconismo hispano», Quaderns d'Italià, 6 (2001), pág. 156.

82 Morales, por ejemplo, escribe: «ocupados nuestros españoles en la conquista de los moros, para recobrar dellos la tierra, más cuidado tenían de la guerra que de la historia» Ambrosio de Morales, Coronica General de España. Prosiguiendo adelante de los cinco libros que el maestro Florián de Ocampo dexó escriptos, Alcalá de Henares, Juan Î́niguez de Lequerica, 1574, sin foliar.

83 En relación a la Poesía, una voz autorizada y cercana como la del padre Feijoo se manifiesta en un sentido idéntico, al defender la naturalidad como elemento constitutivo de la composición poética. Rodrigo Olay VALDÉs, «La poesía y sus constitutivos esenciales según Feijoo», Cuadernos dieciochistas, 16 (2015), págs. 339-370, especialmente 361-368. No es infrecuente localizar en los expedientes de censura múltiples apreciaciones y críticas a quienes emplean un «estilo afectado»; vid. Lucienne Domergue, La censure des libres en Espagne, págs. 121 y 125. 
Del estilo de Feijoo y Berganza nada concreta, si bien está claro que el de este último no le convence nada. En primer lugar afirma, «me parecieron al principio duras algunas expressiones» y a continuación rechaza el exceso de pasión que, sin duda, Berganza pone a su historia, pues bastaban argumentos y razones para llegar a la verdad y defenderla.

\section{Nociones historiográficas: de la búsqueda de la verdad al despojo de la pasión}

La Historia es precisamente una de las preocupaciones de Ania. Ania no es historiógrafo ni llega a ser cronista, sin embargo, aquella se constituye como una de sus aficiones. Los libros de historia no faltaban en su biblioteca particular, como habremos de ver, y las aprobaciones delatan que conoce los cánones del género. Además, en estas últimas, no rehúye nunca el comentario histórico.

Así, en la aprobación a la obra de San Ángel, que distaba de ser un alarde de modernidad en el plano historiográfico, pues permanecía anclada en los tradicionales valores del Carmen, defensores a ultranza de su supuesto fundador, Elías $^{84}$, cuya verdadera historicidad venía siendo cuestionada en los círculos maurinos desde finales del siglo XVII ${ }^{85}$, escribe: «Reduce con increible destreza a una breve lámina la casi inmensa Historia de su religión esclarecida [...] siglos llenos sin interrupción de héroes, triunfos tan continuados hasta las luzes de nuestras cercanías».

Aunque en todas las aprobaciones emite juicios y opiniones, en absoluto exentas de interés sobre el particular, es la pieza paratextual que compone al Ferreras convencido de Berganza la que nos suministra las informaciones más expresivas, si bien no las únicas. Este texto permite a Ania participar en una de las querellas de inicio de siglo. Indirectamente había podido utilizar su pluma en la contienda que contra los errores comunes emprendió Feijoo y, ahora, también indirectamente, toma parte en el acalorado debate que afecta al método historiográfico. Este se va a desarrollar durante buena parte de siglo y ya conoce en su primer tercio una de las disputas más enconadas ${ }^{86}$.

84 Juan de SAN Ángel, Disciplina religiosa, págs. 7, 12, 15...

85 Antonio Mestre Sanchis, «El marco político y cultural de la obra del padre Feijoo», pág. 170.

86 Nos referimos, naturalmente, a la crisis ferrérica. Expone algunos rasgos Jesús Maiso González, «La difícil penetración de la erudición crítica en la España del siglo XVIII», en Francisco Gimeno Blay (ed.), Erudición y discurso histórico: las instituciones europeas (s. XVIII-XIX), Valencia, Universidad de Valencia, 1993, págs. 179-191. Son fundamentales el espléndido trabajo de Ofelia REy Castelao, La historiografía del Voto de Santiago. Recopilación crítica de una polémica histórica, Santiago de Compostela, Universidad de Santiago de Compostela, 1985, págs. 150-156; y el estudio de Antonio Mestre Sanchis, «La erudición, del Renacimiento a la Ilustración», Apología y crítica de España en el siglo XVIII, Madrid, Marcial Pons, 2003, págs. 255-256. Son 
Ferreras convencido era la reacción crítica de Berganza a la Cronología de Juan de Ferreras, que levantó, como el propio benedictino señala, una polvoreda significativa y que le merecía una total reprobación. La oposición es, en primer lugar, en cuestión de método, porque Berganza rechaza el argumento negativo del que fuera bibliotecario real como elemento suficiente para negar un hecho histórico que está además bien atestiguado por la tradición; y, en segundo lugar, porque este retrasaba al siglo vIII la entrada de la regla benedictina que él adelantaba a tiempo de los godos, pues en el monasterio de Cardeña se tenía por tradición que los primeros monjes benedictinos habían llegado en el siglo VI.

Por su parte, Ania lo tenía claro: Ferreras no hacía justicia a la religión benedictina ${ }^{87}$. Del mismo modo, achaca a «esa pluma española acreedora por cierto de más gloriosos vuelos y assumptos», no ser fiel a su patria ${ }^{88}$ y proceder sin método riguroso: despreciando monumentos, archivos, tradiciones y autores que se constituyen como las fuentes de la historia. Además, se sitúa, en la línea de pensamiento de Berganza, pero también, por ejemplo, de Feijoo, en el sentido en el que la ausencia de información coetánea, el silencio de las fuentes, fuera un argumento de peso para esgrimir la negación histórica ${ }^{89}$. El siguiente pasaje no puede ser más expresivo en su oposición al método de Ferreras. Así, al escribir de la obra de Berganza afirma que esta «dissipa con luz activa las nubes de inverosímiles afectados, de argumentos negativos, de chronologías mal texidas y de unas reglas de crítica diminutas y mal practicadas».

también de interés la síntesis de Antonio Mestre Sanchis y Pablo Pérez García, «La cultura en el siglo XVIII español», págs. 419-422; y las páginas que dedica Giovanni SitrFFoni, Veritá della storia e ragioni del potere nella Spagna del primo ‘700, Milán, FrancoAngeli storia, 1989, págs. 170-177.

87 «Unas opiniones que no tuvieron más cuna ni más fundamento que la passión o el capricho de un autor estrangero, poco instruido y mui embidioso de las antiguedades de España y de la Sagrada Religión benedictina». No hace falta añadir que los bernardos seguían la regla de san Benito. El siguiente pasaje de las definiciones de la Observancia castellana de 1584 es testimonio suficiente: «las reglas [...] del glorioso patriarcha nuestro padre San Benito (debaxo de la qual los deste instituto militamos)» Diffiniciones de la Sagrada Orden de Cistel, Salamanca, Herederos de Matthias Gast, 1584, sin foliar.

88 «Pero más abominable es, no desnudarse de estas passiones, sino mudar los trages, vistiendo el ánimo todo de aversión al proprio país y de afición a los estrangeros porque de esta suerte se falta a la verdad de la Historia y se atropella injustamente el honor de la Patria».

89 Para el benedictino en tales términos se expresa Francisco Javier FERnández Conde, «Feijoo y la ciencia histórica», Studium Ovetense, 4 (1976) pág. 108. Para Francisco Fuster, en cambio, Feijoo no «tenía formación en las reglas del oficio», Benito Jerónimo FEIJoo, Reflexiones sobre la historia (edición, introducción y notas de Francisco Fuster), Madrid, Fondo de Cultura Económica, 2015, pág. 17. En cambio, con acierto y rigor, Inmaculada Urzainqui escribe: «Feijoo tiene una mente histórica, posee una impresionante erudición histórica [...] y hace mucha historia aun cuando no sea [...] de manera regular y sistemática» Inmaculada Urzainqui, «Feijoo en los inicios de la historiografía de la cultura», en María Dolores Gimeno Puyol y Ernesto Viamonte Lucientes (coords.), Los viajes de la razón. Estudios dieciochistas en homenaje a María-Dolores Albiac Blanco, Zaragoza, Institución Fernando el Católico, 2015, pág. 110. 
El argumento negativo no es apropiado por lo tanto para el método histórico, pues trae sombras a la disciplina. Así, Ania no rechazaba la historicidad de Elías —uno de esos héroes del Carmen—, como tampoco la llegada benedictina en el siglo VI al monasterio de Cardeña, pues la tradición y la concordancia entre varios autores era suficiente prueba de verdad. Es decir, la historia, su discurso, la anhelada verdad continuaban en nuestro autor bajo el peso de la autoridad.

El tópico de la búsqueda de la verdad se repite de un historiador a otro: la verdad es la ley fundamental en la historia. Surge en el mundo clásico, lo asume la historiografía renacentista y durante toda la Edad Moderna no se va a abandonar ${ }^{90}$. Ania lo tiene claro: no se puede faltar «a la verdad de la historia» y son «archivos, tradiciones, monumentos y autores que concordes establecen la más firme verdad de nuestra Historia». Los monumentos — 'documentos' — son «testimonios del pasado» ${ }^{91}$ y tienen la suficiente entidad como para soportar el edificio historiográfico. En muchas ocasiones se hayan ocultos, luego hay que descubrirlos y sacarlos a la luz. El juicio de Ania no se aleja del espíritu que desde finales del siglo siglo XVI triunfa entre los historiógrafos hispanos. Son muchos los testimonios que pueden aducirse, pero, por ejemplo, en 1681, Francisco de Sota escribía: «Las escrituras de archivos muy antiguos y auténticos son el alma de la Historia por el fundamento infalible de la verdad que en ella se desea ${ }^{92}$. Ania, a propósito del mérito del conde de Aguilar de documentar con cierta base histórica la religiosidad de los profesos de las órdenes militares, la cual se había puesto en duda, escribe:

Solamente sigue el author los fundamentos firmes y sólidos para erigir sobre ellos la gran máquina de esta obra, exponiendo a la luz pública los diplomas pontificios que por seguridad o por incuria estuvieron ocultos por muchos siglos. Y (como decía Cicerón) este modo de persuadir con monumentos y exemplares de antigüedad se escucha con más respeto y mayor gusto en el tribunal de la razón.

Y más adelante expone: «Pudieron estas dudas transformarse en sombras que, ayudadas por la distancia del tiempo, y de los lexos de retirados archivos, [...], hicieron menos perceptible la verdad».

90 Carmen CodoñER, «Un modelo imitativo: la historiografía latina», Studia Historica. Historia moderna, XIII (1995), págs. 23-24. Jenaro Costas Rodríguez, «El tópico de la verdad en la historiografía latina renacentista», en Luis Merino Jerez, Eustaquio Sánchez Salor y Santiago López Moreda (eds.), La recepción de las artes clásicas en el siglo XVI, Cáceres, Universidad de Extremadura, 1996, págs. 543-554.

91 Así los define Pedro Álvarez de Miranda, El léxico de la Ilustración Temprana en España, pág. 185.

92 Fray Francisco de SотA, Chronica de los Príncipes de Asturias y Cantabria, Madrid, Juan García Infançón, 1681, pág. 623. 
Otro de los pilares del discurso historiográfico era despojarlo de todo tipo de afición o apasionamiento ${ }^{93}$. Lo exponía ya en el siglo Xvi Vives: el historiador emitía un juicio y debía hacer «gala de una templanza tal que tu posible censura o alabanza de algún hecho no parezca producto del apasionamiento, sino de la razón $»^{94}$, retomando lo que en realidad era el otro ideal de la historiografía clásica. La pasión no es propia de la historia, pues el desapasionamiento es uno de los rasgos definitorios del género. Así, Ania no duda en afirmar en la censura al texto de Berganza que «es innegable que hará contemptible ['despreciable'] su Historia quien se dexasse arrastrar de la afición de su patria o de aversión ['oposición'] a las estrangeras. Será buen paisano, pero mal historiador». Por eso Ania se opone a los falsos cronicones como demuestra el hecho de que poseyera y seguramente manejara la historia del padre Rogatis. Tiene que haber, no obstante, un punto medio, porque no

[...] más abominable es no desnudarse de estas passiones sino para mudar trages vistiendo el ánimo todo de aversión al proprio país y de afición a los estrangeros porque de esta suerte se falta a la verdad de la historia y se atropella injustamente el honor de la patria.

La palabra pasión se encuentra siempre en Ania con la carga negativa con que Álvarez de Mirada la documenta desde fines del siglo XVII y aún la primera mitad del siglo XVIII. Recordemos que a propósito del tomo tercero del Teatro crítico universal de Feijoo, Ania alababa del padre maestro que huía de «las hinchadas olas de la pasión», poniendo «únicamente la proa y la aguja al norte de la verdad». Sin embargo, no menos cierto es que en el caso de la defensa de la patria, para Ania, peor que caer en el apasionamiento es «tener afición a los extranjeros y aversión al proprio país». Quizás pueda intuirse en este pasaje el origen de lo que más adelante desembocará en la «pasión nacional» y sobre todo se aprecian ciertos rasgos apologéticos en el pensamiento del cisterciense asturiano.

Pero, por encima de este caso, la pasión, el afecto, la inclinación excesiva hacia algo, en suma, la compasión, debían evitarse. De hecho, finaliza la aprobación a Feijoo del siguiente modo: «Sería compasión ['afición, pasión’] privar al público de erudición tan amena y dilatada». La obra del benedictino no era

93 Lo expone con buen criterio Ofelia Rey Castelao, «El peso de la herencia: la influencia de los modelos en la historiografía barroca», Pedralves, 27 (2007), págs. 54-55. Los dos grandes tópicos son «la necesidad de verdad y la imparcialidad».

94 Jenaro Costas Rodríguez, «La verdad en la historiografía renacentista», págs. 551-552. 
de su total agrado, pero reconocía entre otros méritos del autor su erudición ${ }^{95}$, así como la variedad de temas tratados.

\section{La instrucción en materia religiosa}

Entre las cuestiones presentes en el Ferreras de Berganza, es la temprana cronología de la presencia de los benedictinos en la Península uno de los aspectos de los que Ania, como acabamos de ver, se hace eco. Así no es extraño que la materia tratada por San Ángel, la religiosidad del Carmen, le pareciera de la suficiente «gravedad» — nuevo tópico— - y que en la aprobación a Feijoo llamara la atención sobre la defensa de le fe («abate religiosamente las alas de sus discursos, y arroja las firmes áncoras de la Fe, para caminar con seguridad»). Así, no ha de parecer fuera de lugar que se expresara en los siguientes términos a propósito del libro del conde de Aguilar: «El empeño de estas literarias fatigas es el más noble que pudo ofrecerse a un elevado talento, porque es la defensa de la Religiosidad de las Quatro Órdenes [...]. No podía assumpto menos grave (en sentir de Halicarnaseo) ser digno empeño de tan sublime escritor».

La obra de fray Iñigo de la Cruz suponía un ejercicio notable por defender la religiosidad de las Órdenes Militares, en la medida en que tenía que demostrar que efectivamente los caballeros de las órdenes cumplían los tres votos (obediencia, pobreza y castidad), cuestión realmente dificil, sobre todo en lo que atañe al voto de castidad ${ }^{96}$. No obstante, además de hacer acopio de la autoridad de un gran número de autores, sostiene su discurso en el refrendo pontificio a lo largo de los siglos por medio de las diferentes bulas que reconocen a las Órdenes como institutos religiosos.

Por supuesto, Ania expone resumidamente esto que acabamos de enunciar, pero no es lo más significativo. Es mucho más relevante el léxico que emplea, y, dentro de este, el siguiente pasaje es un ejemplo notorio:

Fue indubitable por muchos siglos a los hombres sabios la religiosidad verdadera de las Sagradas Milicias hasta que en nuestra edad de yerro se empezó a disputar o por genio o por política o (lo que para nosotros es más cierto) por no estar instruidos con bastante distinción los principales fundamentos y Bulas Pontificias en que estrive la verdadera Religión Militar.

95 Es una práctica habitual Ignacio García Agullar, Poesía y edición en el Siglo de Oro, págs. 110-112.

96 En su exposición fray Íñigo de la Cruz se centra en demostrar que los caballeros cumplen con el voto, no de forma absoluta, sino de forma mitigada. De este modo, los caballeros no alcanzan la perfección, pero sí cumplen con las obligaciones de la religión, pues no cumplir de forma absoluta no significa no cumplir. 
Y es este un pasaje significativo en la medida en que Ania se refiere a la época que le toca vivir como «edad de yerro» en un momento, además, en el que la noción de siglo ilustrado — «un siglo tan esclarecido»— comienza también a documentarse ${ }^{97}$, si bien y evidentemente sin continuidad. Pero el hecho trascendente, la implicación de esta apreciación que Ania hace de su tiempo me parece significativa. Y lo es porque en un momento en el que nosotros vemos luces, vemos progresos, intuímos y reconocemos los orígenes de la Ilustración, un contemporáneo nos describe una edad de error, de ignorancia ${ }^{98}$, claro está, en materia religiosa, una edad en la que falta instrucción en la materia. Y, sin duda, el desconocimiento de la religiosidad de las Órdenes es mucho más grave dada la importancia que estas tuvieron en la historia de la Reconquista. Expone Ania:

Órdenes Militares, columnas firmíssimas sobre que se erigió la máquina de la Española Cathólica Monarquía con tanta altura que pudieron mirar su altiva coronada frente los ojos del temor y del respeto desde los más distantes y escondidos senos de África, adonde retrocedió en ondas de sangre la corriente que inundaba de estragos y turbantes este Cathólico País, hasta que encontraron en estas firmes columnas freno y castigo a su ímpetu furioso.

Y esta falta de instrucción que Ania encuentra en muchas cuestiones que atañen a la historia de España, especialmente en su vertiente religiosa, y a la fe, son las que le llevan a, en la obra de San Ángel, afirmar que su tratamiento de la Regla del Carmen, por su «literal y moral exposición [...] [, le] merece más gracias que censura». Por supuesto, en materia de instrucción la obra del carmelita se ajustaba a unos cánones mucho más actuales al aceptar la traducción de la regla y los comentarios a la misma al castellano pues no es su

[...] ánimo enseñar con [estas consideraciones] a los Doctos y Religiosos en la virtud prácticos, sino dar algunas noticias a los niños que toman nuestro Santo Hábito, para que con las direcciones de los Maestros de Novicios, y la doctrina que en este corto volumen se abrevia, se enteren mejor de las obligaciones religiosas.

Y añade,

97 Pedro Álvarez de Miranda, El léxico de la Ilustración Temprana en España, pág. 204.

98 Traigamos al caso las palabras de Torres Villarroel, recogidas por Álvarez de Miranda, en que el polémico personaje se refiere a la época que le tocaba vivir, el primer tercio del s. XVIII, en los siguientes términos: «Mal haya edad tan bruta, siglo irracional» (Pedro Álvarez de Miranda, El léxico de la Ilustración Temprana en España, pág. 208). En todo caso, su testimonio ilumina nuevamente la percepción que en los distintos círculos se tenía de los tiempos vividos como tiempos de cambio. El texto data de 1727. 
[...] no me negarán que quantos comentos se han formado de nuestra Santa Regla son singulares los que se tienen a mano, y aun de los más no se tiene noticia: Lo uno, por averse sepultado con el tiempo, que es la polilla de lo más precioso, y hallarse raro exemplar; lo otro, por ser todos en el idioma latino, y componiéndose el cuerpo de la Religión de legos, religiosas, y estudiantes ,si estos entienden el idioma, los demás no lo entienden ${ }^{99}$.

Así pues, Ania expone sus propias ideas en las aprobaciones y lo hace sobre diversas materias: religión, historia, instrucción... En ocasiones sus juicios coinciden con los expuestos por los autores cuyas obras censura. En otras difiere, bien en el contenido, bien en el estilo. Pero, al margen de estas exposiciones que nos permiten intuir su perfil intelectual, Ania realiza su ejercicio literario. Un pasaje de la aprobación al Defensorio sobre la religiosidad nos permite exponer su sistema de razonamiento, que remite a modelos escolásticos:

Religión verdadera es un concepto unívoco y universal que comprehende la religión mitigada y la religión rígida como razones diferenciales o numéricas específicas según la variedad de los authores. Pero sea específica o sea individual la diferencia quando convienen univocamente qualquiera de ellas participa con igualdad toda la substancia del concepto común.

\section{La erudición en el discurso}

La erudición es rasgo común en aprobaciones y censuras ${ }^{100}$. Las citas de autores clásicos o de textos de los padres de la iglesia no faltan tampoco en las piezas paratextuales que Ania compone. Así, en la censura a la obra de San Ángel son muy abundantes las citas a las epístolas de Casiodoro. Por supuesto, tampoco falta San Bernardo. No obstante, quizás sea más llamativo el pasaje que toma de un humanista como Lipsio para lanzar una comparación con la obra que ahora juzga: le merece a él este texto del carmelita tanto elogio como a Lipsio los diálogos de Quintiliano ${ }^{101}$. Y es este un aspecto interesante en la medida en que permite reconocer la influencia del humanismo crítico europeo en la Ilustración temprana, realidad sobre la que hace unos años A. Mestre

\footnotetext{
99 Juan de SAn Ángel, Disciplina religiosa, pág. 19.

100 Alain BÈGue, «La poesía a la luz de las aprobaciones (siglos XVII-XVIII)», pág. 98.

101 El pasaje figura en Justo Lipsio, C. Cornelii Taciti. Opera quae extant, Amberes, Chistophorum Plantinum, 1585, pág. 43.
} 
llamaba la atención ${ }^{102}$, pues Lipsio, que era conocido en España desde el siglo XVII ${ }^{103}$ y leído desde entonces, también fue lectura de Martí, Mayans, Pérez Bayer y compañía. Al mismo tiempo, sospechamos que sus obras no debían formar infrecuentemente parte de bibliotecas conventuales o de monjes particulares.

No obstante, las citas más habituales son, como no podía ser de otro modo, las de los clásicos latinos (Quintiliano, Quinto Curcio, Cicerón, Fedro...) y las de los padres de la Iglesia (fundamentales las referencias a las epístolas de Casiodoro...) concentradas, estas últimas, fundamentalmente en el paratexto a la Disciplina religiosa.

Finalmente, hay en uno de los paratextos de Ania un párrafo en el que desfilan los nombres de Tácito, Livio y Floro, aunque no para ofrecer pasajes de ninguno de ellos. Ania compara el método, el estilo, del carmelita San Ángel con el empleado por los tres grandes historiadores romanos. El pasaje merece la pena reproducirlo por la imagen que tiene del discurso en cada uno de ellos: «Quizá porque no se registran aquí»—escribe— «sutilezas o malicias de un Tácito, profanas discussiones de un Livio, ni hermosos vanos periodos de un Floro». De modo que de estos autores no tiene Ania la misma percepción que tenía, por ejemplo, Feijoo, para quien Floro era elegante (TC, II, 7, § VII, 33) y Livio un modelo a seguir (TC, Iv, $8, \S$ v, 13). Mientras, Tácito era el modelo para Mayans ${ }^{104}$.

\section{Biblioteca personal y lecturas del padre Ania ${ }^{105}$}

La mayoría de las citas anteriores no nos son de utilidad para conocer ni el contenido de la biblioteca del padre Ania ni las lecturas que este, en efecto, llegó a realizar. Sabido es que los clásicos se conocían habitualmente a través de recopilaciones, de modo que estos pasajes apenas nos sirven para conocer qué

102 La lectura de los humanistas críticos por los novatores ha sido señalada por Antonio MESTRE SANCHIs, Humanistas, políticos e ilustrados, Alicante, Universidad de Alicante, 2002, págs. 13-14, 68 y 86-87.

103 Beatriz Antón Martínez, «El humanista flamenco Justo Lipsio y la receptio del tacitismo en España,» en José María Maestre Maestre y Joaquín Pascual Barea (coords.), Humanismo y pervivencia del mundo clásico, I, Cádiz, Universidad de Cádiz, 1993, págs. 237-249.

104 Francisco Javier Fernández Conde, «Feijoo y la ciencia histórica», págs. 78 y 99. El benedictino proponía como modelos a Tácito y Livio junto a Salustio. Del primero admiraba su estilo; del estilo de Floro no dudará en tildarlo de elegante. Para Mayans el modelo a imitar en el campo de la historia era Tácito. Lo señala Antonio Mestre SAnchis, Humanistas, políticos e ilustrados, pág. 81.

105 Las notas que a continuación se exponen han sido compuestas a partir de los ejemplares que de Ania hemos logrado localizar en la Biblioteca Pública del Estado de León. Agradecemos a su director don Alfredo Díez Escobar las facilidades para la consulta de los mismos y el trato dispensado. 
autores tenían entonces el rango de autoridad ${ }^{106}$. En este sentido, mayor valor tiene el testimonio citado en el que se expresa sobre el carácter del discurso en Tácito, Livio o Floro, en la medida en que, dado que esta opinión no coincide con la de otros autores, nos permite reconocer una preferencia personal del propio Ania. Si los conocía a través de ediciones de sus obras o de recopilaciones misceláneas es otra cuestión más difícil de dilucidar. Más aún saber si estas componían su biblioteca personal o alguna de las librerías monásticas a las que pudo tener acceso.

No obstante, merece la pena aproximarse a los fondos que integraban la primera, pues como ha expuesto Hevia Ballina, a propósito de la librería personal del padre Feijoo: «La biblioteca personal de cualquier estudioso sirve por sí misma, en primera instancia, para delinear el perfil intelectual de su dueño» ${ }^{107}$. Sabemos que a su muerte los libros que llegó a acumular en vida pasaron a su monasterio de profesión. Algunos todavía se conservan hoy. Así, por ejemplo, en la portada de la parte sexta de la Historia della perdita e Riacquisto della Spagna occupata da mori del padre Rogatis puede leerse el exlibris «Fray Joachimus ab Ania». Mientras, en el verso de la portada de las partes IV y v figura «Ad ussum Fray Ioachimi ab Ania. Saltus Novalis Filii», formato en absoluto inusual ${ }^{108}$. Todos ellos iban encuadernados en pergamino.

Los tres tomos de la Historia de la Reconquista de España del padre Rogatis habían tomado carta de naturaleza tras haber llegado a manos del italiano uno de los engendros más despreciables de la cronística hispana: La verdadera historia del rey don Rodrigo escrita por el árabe Abulcacino Taristo y traducida por Miguel de Luna. Así lo expresa el propio Rogatis en el prólogo del tomo $\mathrm{I}^{109}$. Es cierto, como señala François Lopez, que la posesión de un libro no es garantía suficiente para aseverar que este haya sido leído por su posesor ${ }^{110}$, sin embargo, no deja de resultar atractivo apuntar esta posibilidad en un hombre que no tenía solo, como hemos intentado ver más arriba, un conocimiento preciso sobre el género histórico sino que además rechazaba los principios que

\footnotetext{
106 Ofelia Rey Castelao, «La influencia de los modelos en la historiografía barroca», pág. 51.

107 Agustín Hevia Baldina, «Un nuevo acercamiento al padre Feijoo: el catálogo de la librería del monasterio de San Vicente de Oviedo», Studium Ovetense, 8 (1980), pág. 311.

108 Ofrece algunos ejemplos similares Agustín Hevia Ballina, «La librería de Santa María de Valdediós», en Guillermo Mañana Vázquez (coord.), Valdediós. Libro Conmemorativo del mc Aniversario de la Consagración del templo de San Salvador de Valdediós, el conventín, Oviedo, Arzobispado de Oviedo-Caja de Asturias, 1993, págs. 111-115.

109 Bartolomeo DE Rogatis, Historia della perdita e Riacquisto della Spagna occupata da mori. Parte sesta, Bolonia, Gioseffo Longhi, 1684.

110 François Lopez, Hacia una historia de la lectura, Conferencia pronunciada el día 19 de noviembre de 2004 en el Centre Cultural Bancaixa (Sala Cavanilles), de Valencia, Valencia, Societat Bibliogràfica Valenciana Jerónima Gales, 2005, pág. 11.
} 
guiaban la composición de obras históricas sustentadas sobre la pasión y no sobre la verdad como era el caso de los falsos cronicones. En fin, en todo caso, incuestionable es que en su biblioteca personal, como en las librerías de otros muchos regulares, había libros de historia ${ }^{111}$.

Entre los fondos de su biblioteca, la literatura italiana no estaba mal representada. Junto a los tres volúmenes referidos existía un nutrido conjunto de impresos procedentes del país transalpino. Entre ellos, quizás nos interese ahora el ejemplar del texto apologético — en su versión italiana—Successi principali della Monarchia di Spagna nell'anno MDCXXXIX de otro historiador, el erudito boloñés Virgilio Malvezzi ${ }^{112}$ que fue, a la sazón, una de las vías por las que se produjo tanto la introducción del estilo lacónico ${ }^{113}$ como la receptio de Tácito en España ${ }^{114}$. De la otra, aún más influyente, la de Lipsio, ya dejamos constancia más arriba, pues Ania conocía la obra del humanista flamenco, quien no suele ser cita habitual en censuras y aprobaciones. La referencia se debía a un conocimiento directo, pues el asturiano poseía la obra lipsiana en una de las ediciones plantinianas ${ }^{115}$.

Junto a los libros de historia, de política o de raigambre humanista, no estaba mal representada tampoco, entre los volúmenes que por el momento conocemos, la poesía. No faltaban tratados de versificación, manuales de poética latina, como el Elegantiarum poeticarum per locos communes... de Jean Blumerel $^{116}$, que reimpreso varias veces durante buena parte del siglo XVII ${ }^{117}$, conocería sus últimas ediciones al inciar el último tercio de centuria ${ }^{118}$. Mientras, del conjunto de títulos en verso quizás sea las Siete Jornadas del Mundo creado, del Tasso, el volumen de inspiración contrarreformista del poeta italiano, el que mejor representa el espíritu de Ania.

111 No solían faltar libros de historia en las bibliotecas de los monjes cistercienses de fines del siglo XVII e inicios del XVIII, rasgo, por otra parte, compartido con los conventuales de otros institutos religiosos. A este respecto pueden verse las lúcidas páginas de Ofelia Rey Castelao, Libros y lectura en Galicia. Siglos XVI-XIX, Santiago de Compostela, Xunta de Galicia, 2003, págs. 385-388.

112 El volumen se sustentaba sobre una amplísima base documental. Expone su proceso de elaboración Daniel García Vicens, «Sobre las fuentes manuscritas de Sucesos Principales de Virgilio Malvezzi», Studia Aurea, 4 (2010), págs. 209-226.

113 Jorge García LóPEz, «Apuntes sobre Virgilio Malvezzi y el laconismo hispano», págs. 155 y ss.

114 Beatriz Antón Martínez, «Justo Lipsio y el tacitismo en España», pág. 238.

115 Concretamente tenía en sus manos una veintena de los trabajos del humanista flamenco que, a inicios del siglo XVII, salieron de las prensas de Juan Moretus.

116 Johann Blumerel, Elegantiarum poeticarum per locos communes digestarum flores ex optimis quibusque authoribus collecti et tertia hac edition multis additionibus titulis locupletati, Rouen, Ioannem de Manneville, 1653.

117 Emmanuelle Chapron, «Le Gradus ad Parnassum. Pratiques éditoriales et usages familiers d'un dictionnaire poétique latin (xvIIe-XvIIIe siècles)», Bulletin du bibliophile, 2 (2013), págs. [291-292].

118 La última edición que conozco es la de Torino de 1670 que corrió a cargo de la tipografía de Bartolomé Zapata. 
El círculo de lecturas de Ania, sin embargo, no podemos cerrarlo sin una última anotación. Un pasaje del polémico impreso de 1713-1714 nos ofrece también informaciones sobre las lecturas y la doctrina que sigue y defiende en el ámbito del Derecho Canónico. Merece la pena reproducirlo:

No negamos al padre procurador Fray Pedro Sánchez ser conforme a los Sagrados Cánones la libertad de las elecciones, pero estrañamos que, ostentándose tan canonista, no aya tropezado con las doctrinas de Fagnano y el Cardenal de Luca sobre este punto. Enseñan que quando una Religión está dominada de alguna facción es impracticable en ella el derecho común y necessaria providencia especial porque la facción no se haga perpetua y que esta es la práctica que han observando [sic] siempre los Summos Pontífices ${ }^{119}$.

Las referencias al cardenal de Luca y a Fagnano son de interés, pues la obra jurídica de ambos era muy conocida en la primera mitad de la décimoctava centuria. La obra del primero, por ejemplo, tenía lugar habitual en la correspondencia cruzada entre el abogado valenciano José Nebot y Gregorio Mayans ${ }^{120}$. A su doctrina también recurrió el padre Feijoo ${ }^{121}$. Y, además, sabemos que los monasterios cistercienses procuraron dotarse de la edición de 1734 de alguna de sus obras ${ }^{122}$, lo que viene a confirmar su vigencia en los ambientes de la Observancia durante todo el primer tercio de siglo.

Otro tanto puede decirse de la obra de Fagnano. También conoce ediciones a lo largo del primer tercio del siglo XVIII ${ }^{123}$, no falta en las librerías monásticas y, en última instancia, sabemos que el propio Mayans recurrió a sus doctrinas ${ }^{124}$.

Es decir, tenía su propio concepto de los autores clásicos, conocía en detalle los textos de los padres de la iglesia y, como no podía ser de otra manera, las Sagradas Escrituras ${ }^{125}$. Manejó con gusto y soltura los textos de los humanistas

119 Biblioteca Universitaria de Zaragoza.- G-72-424(5) [Memorial de Ania y San Martín, fols. 3r.-3v.].

120 Antonio Mestre Sanchis (ed.), Epistolario iv: Mayans y Nebot (1735-1742). Un jurista teórico y un práctico, Oliva, Ayuntamiento de Oliva, 1972, págs. 181-184, 493-494...

121 Agustín Hevia Ballina, «El catálogo de la librería de San Vicente de Oviedo», pág. 318.

122 En el monasterio de San Clodio había, al llegar la desamortización, un ejemplar del Theatrum veritatis et iustitiae, Venecia, 1734. Ascensión Enjo Babío y Beatriz López Mira, «La biblioteca del monasterio de San Clodio en la Desamortización de Mendizabal», en VV. AA., II Congreso sobre el Císter en Galicia y Portugal I, Ourense, Xunta de Galicia, 1998, pág. 286.

123 En el monasterio de San Vicente de Oviedo hay una edición de 1729 de una de sus obras, Agustín Hevia Ballina, «el catálogo de la librería de San Vicente de Oviedo», págs. 312 y 329.

124. Antonio Mestre Sanchis (ed.), Obras Completas [de Gregorio Mayans] Iv. Regalismo y Jurisprudencia, Oliva, Ayuntamiento de Oliva, 1983, págs. 161 y 216.

125 En uno de sus textos encontramos la referencia al Libro de Ester. Biblioteca Universitaria de Zaragoza.- G-72-424(5) [Memorial de Ania y San Martín, fol. 6r.]. De otro lado, él mismo se intitulaba doctor en 
críticos del círculo flamenco y su afición por la historia le llevó a acumular algunos títulos en su biblioteca personal. Desde su etapa de estudiante sintió inclinación hacia el verso y mantuvo su afición a la poesía ${ }^{126}$. Finalmente, tuvo un conocimiento exacto de los autores que entonces eran autoridades en Derecho Canónico.

\section{Conclusiones}

De todo lo expuesto pueden extraerse una serie de conclusiones que me parecen bastante seguras.

El padre Ania fue, en el primer tercio del siglo XVIII, uno de los religiosos de mayor prestigio de entre los que profesaron en los claustros de la Congregación cisterciense de Castilla. Entre los bernardos castellanos, ostentó sucesivamente cargos de relevancia desde el punto de vista político. Mientras, sus residencias madrileñas le facultaron para establecer contactos y entrar en relación con algunos círculos eclesiásticos de la Corte. En 1716, en la aprobación a San Ángel manifiesta que las obras de este habían recibido el aplauso y la admiración de toda la Corte, escaparate en el que Ania pretendía mostrarse ${ }^{127}$. Si hacemos caso a Feijoo y a Sarmiento, también debió de estar próximo a algunos círculos del franciscanismo hispano. El hecho de que se recurra a él desde la vicaría madrileña para actuar como aprobante o censor muestra, en efecto, que era un hombre valorado en determinadas esferas de la iglesia castellana o, al menos, que gozaba del favor de algunas personalidades de esta ${ }^{128}$. Finalmente, fuera de ambientes eclesiásticos, hemos visto cómo don Î̃nigo de la Cruz también solicitó de su dictamen para aderezar su defensa de la religiosidad de los caballeros militares, señal inequívoca de que no eran pocos los que confiaban en su juicio.

Fue un hombre que no rehusó la polémica y que participó en algunos de los más enconados debates del primer tercio de siglo. Directamente se involucró,

Sagrada Teología. A modo de ejemplo puede verse en Juan de SAN Ángel, Disciplina religiosa, aprobación de Ania.

126 Se ha resaltado el lugar que ocupa la poesía en la instrucción durante el Antiguo Régimen, JeanMarc BuiguÈs, «La razón de la enseñanza. La poesía en los colegios jesuitas del siglo XviII: pedagogía y bibliotecas (1758-1767)», Cuadernos de Estudios del Siglo XVIII, 25 (2015), págs. 22-23 y ss.

127 En el mismo sentido se ha manifestado Víctor Pamplega Pedreira, Las redes de la censura en el siglo XVIII, pág. 186.

${ }_{128}$ Era, en todo caso, uno de los muchos religiosos que actuó a petición del vicario eclesiástico madrileño, muchos de ellos de residencia madrileña. Sobre esta realidad a fines del Antiguo Régimen Lucienne Domergue, La censure des libres en Espagne, págs. 71-72. También, Fernando Durán López, «Regalías, traducciones y devociones», págs. 78-79. 
como hemos expuesto en otro lugar, en la contienda que tuvo lugar en el seno de su Congregación, tras la cuál subyacía también una cuestión que aflorará abiertamente en los dos restantes tercios del siglo, el enfrentamiento entre regalistas y antirregalistas. Ania, sin negar las atribuciones regias, en materia de fe situaba siempre por encima a la figura del Pontífice. De hecho, hemos visto cómo, en sus aprobaciones - aunque solo disponemos de cuatro textos-, no manifiesta que las obras no atentan contra las regalías de su majestad ${ }^{129}$.

En el ámbito de las disputas literarias e intelectuales participó indirectamente al habérsele encomendado las aprobaciones de las obras de Feijoo y Berganza. En esta última manifiesta su rechazo frontal a los planteamientos metodológicos de Ferreras (especialmente el argumento negativo) y, tanto en ella como en la aprobación al Defensorio de Íñigo de la Cruz, se muestra, por un lado, cercano a los tradicionales canónes del género historiográfico, próximo a la verdad y ajeno a las pasiones, y, por el otro, coincidente con el método histórico que se profesa en los círculos benedictinos de la Congregación de Valladolid, uno de cuyos principales objetivos era la iluminación de la historia con documentos (monumentos) que se hacía preciso obtener de olvidados archivos ${ }^{130}$. Por supuesto, no se podía atentar contra las glorias nacionales, bien atestiguadas por la tradición. Se identifica en Ania el sentir apologético de la época.

Una de las preocupaciones del asturiano es la instrucción y especialmente la instrucción en materia religiosa. En ella insiste tanto en la aprobación a la Disciplina religiosa como en la que redacta al Defensorio sobre la religiosidad. Identifica los tiempos que le ha tocado vivir como una edad de yerro, esto es de error, marcada por una falta de instrucción en materia religiosa y un desconocimiento de los valores históricos que sustentan esta. La expresión sirve para documentar que Ania era consciente del tiempo de cambio en que vivía.

En lo que atañe al vocabulario empleado, cabe concluir que los conceptos de que se sirve, la relación entre palabras e ideas (luz, luzes, pasión, verdad, crítica, erudición, gravedad, razón, patria...), sigue los senderos del pensamiento de la época y no hay nada en ellos que nos permita ver en Ania a un hijo de un tiempo nuevo. Es más, y añadiendo un último ejemplo, un término como sublime lo emplea en el sentido retórico tradicional, como sinónimo de 'grave', de 'alto',

\footnotetext{
129 No obstante, este hecho no es decisivo. Un personaje cercano al rey como podía ser su médico de Cámara, don José Suñol, omitía el texto de las regalías.

130 José Antonio Fernández FlóreZ, «La Congregación benedictina de Valladolid en el siglo XVIII», en Francisco Gimeno Blay (ed.), Erudición y discurso histórico: las instituciones europeas (s. XVIII-XIX), Valencia, Universidad de Valencia, 1993, págs. 101-128.
} 
y no, por ejemplo, como tiempo después lo llegará a utilizar Cadalso ${ }^{131}$. Es decir, el análisis del léxico no hace sino corroborar lo que acabamos de exponer sobre sus nociones historiográficas, su participación en los asuntos de su Observancia o sus inquietudes en materia de religión.

Poseía un buen dominio de las autoridades en derecho canónico, conocía los textos de los humanistas críticos y tenía su propia opinion sobre las virtudes de estilo de los autores clásicos. Llegó a formar una biblioteca personal de la que de momento sabemos más bien poco: que estaba dotada de algunos libros de historia, terreno en el que las aprobaciones nos permitían intuir que poseía conocimientos precisos. Desconocemos su entidad, pero no que en ella había libros de pequeño formato, encuadernados en pergamino, impresos lejos de tierras peninsulares, mayoritariamente de procedencia italiana y escritos, bien en esa lengua, bien en latín. Los había en verso y en prosa. De este modo, los escasísimos materiales recuperados, no hacen sino corroborar —es cierto que de momento parcialmente - el testimonio de fray Roberto Muñiz, quien hacia 1793 decía del padre Ania: «Sujeto muy estudioso y versado en las lenguas italiana y francesa, como lo demuestran los muchos y exquisitos libros que dejó a su monasterio» ${ }^{132}$.

Ya por último y en otro plano cabe finalizar afirmando que aprobaciones y censuras son textos que se atienen a una estructura muy definida (identificación del censor, orden para la composición de la aprobación, elogio del autor, esbozo sobre su estilo y desmenuzado del contenido de la obra, entrando, si se estima conveniente, en el análisis de alguna cuestión concreta, y, ya por último, la certificación de que la obra no atenta ni contra la fe ni las buenas costumbres. Cierran lugar, fecha y firma) y que se muestran operativos para el estudio no solo del perfil literario de sus autores sino que permiten esbozar ciertos rasgos de su personalidad intelectual.

131 Isabel VÁzQuez de CASTro, «Hacia un nuevo sentido de lo sublime: un aspecto del léxico en Cadalso», en VV. AA., Coloquio internacional sobre José Cadalso (Bolonia 26-29 de octubre de 1982), Bolonia, Abano Terme, 1985, pág. 319.

132 Roberto MuñIZ, Biblioteca cisterciense, pág. 28. 